\title{
Paraplegia
}

\section{Ramp Length/grade Prescriptions for Wheelchair Dependent Individuals}

\author{
I. Canale, ${ }^{1}$ F. Felici, ${ }^{2}$ M. Marchetti, ${ }^{2}$ B. Ricci ${ }^{3}$ \\ ${ }^{1}$ Center for Neuromotor Rehabilitation, Santa Lucia Clinic, via Ardeatina 306, 00179 \\ Rome, ${ }^{2}$ Institute of Human Physiology, Faculty of Medicine and Surgery, Rome \\ University "La Sapienza", "Visiting Research Professor, Institute of Human \\ Physiology, Faculty of Medicine and Surgery, Rome University "La Sapienza" and \\ Professor Emeritus, University of Massachussetts, Amherst, MA, 01003 USA.
}

\section{Summary}

The aim of this work was to provide well defined criteria for ramp construction for wheelchair dependent individuals (WDI). Force capability was measured in a large sample (140) of WDI, who presented different levels of motor impairment. Levels of impairment were established on the basis of the answers given in a questionnaire regarding the degree of self sufficiency at home as well as outside the home and active participation in sports events. Taking into account those WDI who exhibited at least a minimal level of selfsufficiency, the following prescriptions are indicated. For a 1 metre ramp length, allowable maximal incline 15\%; up to 3 metre ramp length, maximal incline 10\%. The reliability of such prescriptions was confirmed by having a test ramp traversed by 43 WDI. These values are suggested as confidence limits when faced with public building accommodations. Special prescriptions could be adopted for selected populations of WDI. Key words: Wheelchair dependent individuals; Ramp prescriptions.

The quality of the life of wheelchair dependent individuals (WDI) is dependent upon a number of factors. Regardless of the nature of the pathology that forces one to the chair, she/he will necessarily meet difficulties related with the everyday life at home and outside of home. One of the most frequently encountered is represented by gradients, thus the necessity to provide WDI with facilities that can help them in managing such architectural barriers. The focus of this paper is the human-powered wheelchair and the identification of the most propitious length/ grade to be adopted in ramp construction for WDI.

An increasing number of studies dealing with biomechanical aspects of wheelchair propulsion have appeared (Van Der Woude et al., 1988; Sanderson and Sommer, 1985; Sawka et al., 1981; Cerquiglini et al., 1981; Sawka et al., 1980; Cass and Camp, 1979; McLaurin and Brubacker, 1979). In a previous paper (Cappozzo et al., 1991) the problem of ramp traversability was faced using the classical biomechanical approach. The relationship existing between ramp/length traversability and individual maximal voluntary isometric contraction (MVC) exerted by 
WDI on both wheel rims has been envisioned using a mathematical model of the mechanical system represented by man plus wheelchair. The provisional data thus obtained were verified on a sample of selected subjects. Results of this study allowed us to indicate the length and incline of a ramp which each WDI could be expected to successfully manage provided his/her MVC has been previously measured. On the basis of these results we have established a rationale for building ramps. In this study, our objectives included the:

1. Measurement of MVC of a statistically significant sample size.

2. Correlation of MVC with significant parameters such as age, sex of subjects, etc.

3. Verification of our prescriptions using a specified length/incline test ramp to be traversed by a consistent number of WDI.

\section{Methods}

\section{MVC measurements}

Initially, 182 subjects, all WDI, participated in this study. Each subject performed the required activities in the rehabilitation centre in which she/he resided and in her/his own wheelchair. Of the 182 subjects, 120 were males and 62 were females. All participated on a voluntary basis and all gave informed consent. In addition, all subjects were given the assurance of anonymity and all safeguards were carried out in strict accordance with University and Rehabilitation Centre policy.

A questionnaire was completed by each subject during the research familiarisation period. In addition to name, sex, age, height, and weight, classification of spinal lesion and diagnosis of neuromuscular deficit was noted for each subject.

Other information related to self-sufficiency outside home ( $\mathrm{SSOH})$ and active sport experience (ASE). Additional information was obtained under each category, e.g., SSOH: drives car, performs shopping duties, and travels including visits to public buildings; ASE: kind of sport(s) engaged in on a regular basis, either currently or within the past 6 months. Thus, a profile of the activities of daily living (ADL) was obtained for each subject.

Measurement of MVC was achieved as depicted in Figure 1. The wheelchair was securely blocked and through a chain arrangement was secured to a wall. A piezoelectric force transducer (Kistler, model 9203), attached to the chain and connected to its amplifier (Kistler, model 5001), permitted the measurement of the

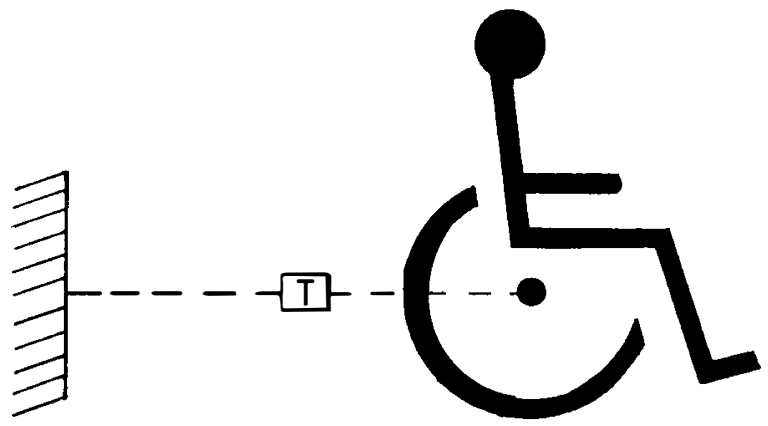

Figure 1 Scheme for MVC estimations; T indicates transducer. 
Table I Subject profile. For each parameter $\overline{\mathrm{X}} \pm 1 \mathrm{SD}$ are reported

\begin{tabular}{|c|c|c|c|c|c|}
\hline Condition & $\mathrm{N}$ & Sex & $\begin{array}{l}\text { Age } \\
(\mathrm{yr})\end{array}$ & $\begin{array}{c}\text { Stature } \\
(\mathrm{cm})\end{array}$ & $\begin{array}{c}\text { Weight } \\
(\mathrm{kg})\end{array}$ \\
\hline \multirow[t]{2}{*}{ All subjects } & 86 & M & $42 \pm 19$ & $170 \pm 25$ & $65 \pm 16$ \\
\hline & 54 & $\mathrm{~F}$ & $50 \pm 22$ & $160 \pm 7$ & $58 \pm 14$ \\
\hline All subjects & 72 & $M$ & $35 \pm 12$ & $174 \pm 16$ & $67 \pm 11$ \\
\hline age $<65$ & 39 & $\mathrm{~F}$ & $37 \pm 13$ & $161 \pm 7$ & $58 \pm 12$ \\
\hline Sport & 39 & $M$ & $30 \pm 7$ & $171 \pm 34$ & $62 \pm 16$ \\
\hline participation & 22 & $\mathrm{~F}$ & $29 \pm 8$ & $161 \pm 7$ & $54 \pm 9$ \\
\hline Public & 56 & $M$ & $33 \pm 12$ & $175 \pm 17$ & $67 \pm 10$ \\
\hline building usage & 24 & $\mathrm{~F}$ & $32 \pm 8$ & $160 \pm 7$ & $54 \pm 8$ \\
\hline \multirow[t]{2}{*}{ Car drivers } & 49 & $M$ & $33 \pm 11$ & $176 \pm 18$ & $66 \pm 10$ \\
\hline & 15 & $\mathrm{~F}$ & $33 \pm 9$ & $159 \pm 8$ & $53 \pm 9$ \\
\hline Shopping & 54 & $M$ & $33 \pm 12$ & $176 \pm 17$ & $67 \pm 11$ \\
\hline independently & 25 & $\mathrm{~F}$ & $31 \pm 9$ & $161 \pm 7$ & $54 \pm 9$ \\
\hline
\end{tabular}

propulsive component of force exerted by the subject on the wheel rim. Each subject was instructed to exert his/her MVC by pushing on both wheel rims. On the basis of an earlier study conducted in this laboratory (Cerquiglini et al., 1981), three different positions of the hands on the wheel rim were investigated: (a) grasp at the top of the wheel, i.e., 90 degrees from floor surface; (b) grasp 30 degrees forward with respect to the vertical; and (c) grasp 30 degrees rear with respect to the vertical. This latter position, i.e., rear vertical grasp, is the one which is most frequently used by wheelchair dependent persons in the initial phase of ramp ascent. All three grasp positions correspond to those assumed by WDI during the propulsion phase of ramp ascent.

By the use of a self-selection process, subjects who were unable to attain the minimum force application levels in one or more of the three basic, pre-selected, wheel rim positions were excluded. Reasons advanced for subjects not being able to exert sufficient force were related primarily to level of spinal cord lesion and in small measure to senescent atrophy. By this mean, 42 subjects were excluded and the final number of subjects included in this study was reduced to 140 (see Table I).

All data were fed into a personal computer (Olivetti M24) for analysis.

\section{Verification of ramps}

In order to test the prescription obtained by MVC measurements, two ramps of 3 and 6 metres length and 12 and $10 \%$ incline respectively had been assembled in the gymnasium of Santa Lucia Center. All subjects who participated to the recreational activities of the Center were requested to try the ascent of the two ramps. 43 WDI consented to perform the tests.

\section{Results}

As one can observe from Table II, there are negligible differences in force attained by WDI with different placement of the hands on the wheel hand-rim. An analysis 
Table II MVC applied force expressed as percentage of body plus wheelchair weight $(\mathrm{N} / \mathrm{N})$ for indicated positions on wheel rim. For each parameter, $\overline{\mathrm{X}} \pm 1 \mathrm{SD}$ is reported

\begin{tabular}{lrcrrr}
\hline & \multicolumn{4}{c}{$\begin{array}{c}\text { Position of hand on wheel rim } \\
-30^{\circ}\end{array}$} & $\begin{array}{c}0^{\circ} \\
+30^{\circ}\end{array}$ \\
\hline All subjects & 140 & $0.25 \pm .2$ & $0.27 \pm .18$ & $0.24 \pm .17$ \\
Males & 86 & $0.31 \pm .2$ & $0.32 \pm .19$ & $0.29 \pm .18$ \\
Females & 54 & $0.18 \pm .14$ & $0.19 \pm .12$ & $0.17 \pm .12$
\end{tabular}

Table III MVC expressed as the ratio of measured force and body plus wheelchair weight. For each paramether, $\overline{\mathrm{X}} \pm 1 \mathrm{SD}$ is reported

\begin{tabular}{lccc}
\hline Condition & N & Sex & $\begin{array}{c}\text { MVC } \\
(\mathrm{N} / \mathrm{N})\end{array}$ \\
\hline All subjects & 86 & $\mathrm{M}$ & $.38 \pm .25$ \\
& 54 & $\mathrm{~F}$ & $.23 \pm .16$ \\
All subjects & 72 & $\mathrm{M}$ & $.44 \pm .24$ \\
age $<65$ & 39 & $\mathrm{~F}$ & $.28 \pm .16$ \\
Sport & 39 & $\mathrm{M}$ & $.56 \pm .22$ \\
participation & 22 & $\mathrm{~F}$ & $.35 \pm .15$ \\
Public & 56 & $\mathrm{M}$ & $.53 \pm .21$ \\
building usage & 24 & $\mathrm{~F}$ & $.34 \pm .16$ \\
Car drivers & 49 & $\mathrm{M}$ & $.54 \pm .21$ \\
& 15 & $\mathrm{~F}$ & $.33 \pm .15$ \\
Shopping & 54 & $\mathrm{M}$ & $.53 \pm .21$ \\
independently & 25 & $\mathrm{~F}$ & $.34 \pm .16$ \\
\end{tabular}

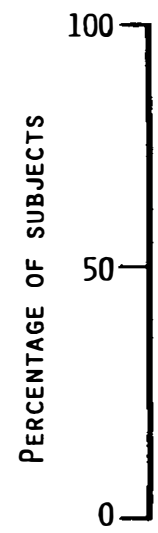

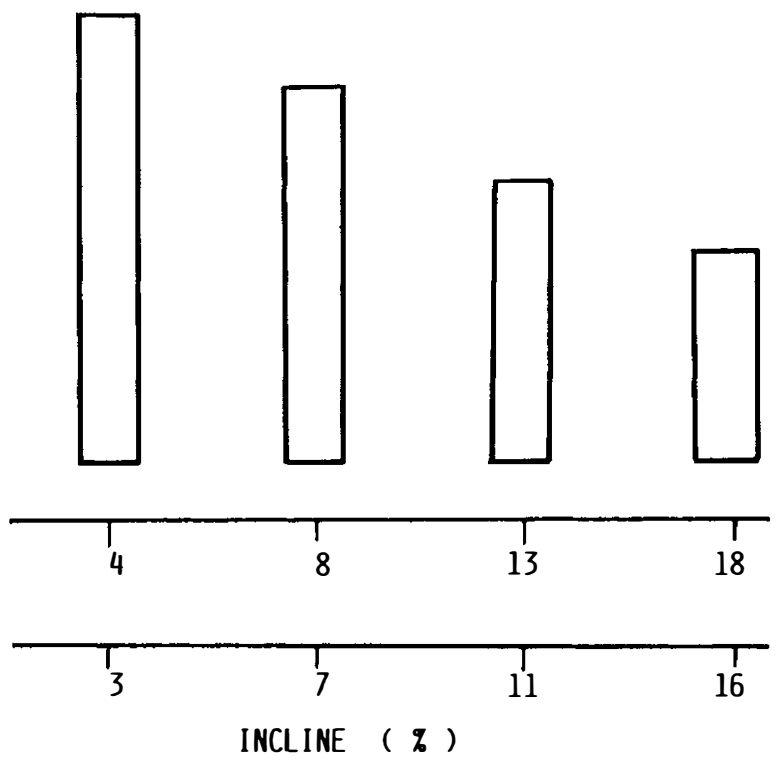

Figure 2 Histogram describing ramp length/grade relationships for all subjects. 


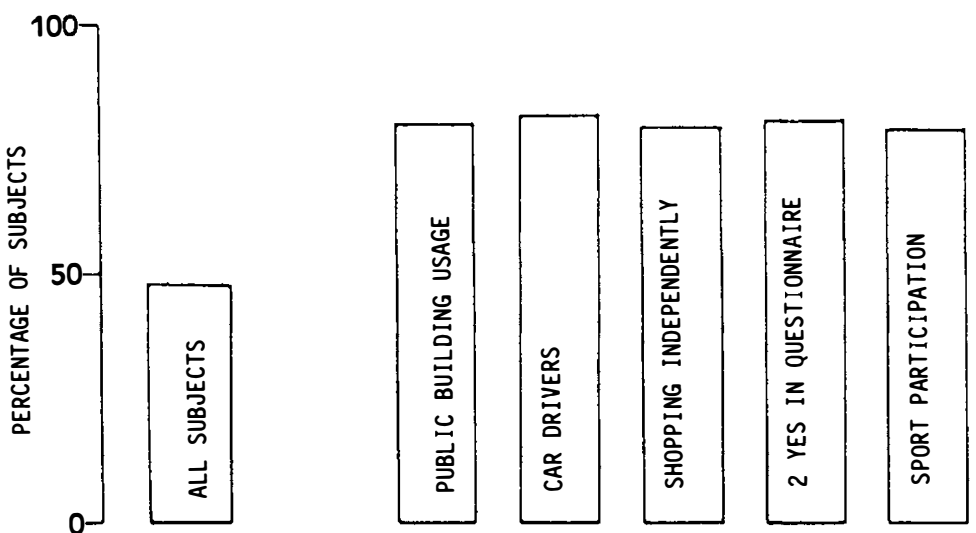

Figure 3 SSOH group, indicated above, expressed as percentage of subjects able to ascend 1 metre ramp length at $16 \%$ grade (or 6 metres at $11 \%$ or 3 metres at $13 \%$ ).

of the same table not surprisingly reveals that the weaker individuals are the female subjects, inasmuch as these estimations were of absolute force capability. Their exerted force capability is approximately one-half that of the male subjects. In Table III is reported the mean force capability of each category of subjects we selected on the basis of the questionnaire: the stronger individuals are those with previous history of sport participation. These subjects also demonstrated selfsufficiency. Thus, they are included in one or more of the SSOH categories.

In accordance with the ramp length/grade criteria reported earlier (Cappozzo et al., 1991), the maximum incline which can be comfortably traversed may be inferred from MVC measures. In Figure 2 are reported histograms showing the percentage of total population having a force availability convenient to ascend the indicated grades considering ramp lengths of 3 and 6 metres respectively. From Figure 2 , one can observe that approximately $80 \%$ of the 140 subjects were able to climb ramps of $8 \%$ grade for 3 metres length and $7 \%$ grade for 6 metres. A comparison among the different groups of Table I, is shown in Figure 3. When compared with all subjects, the SSOH group is seen to be capable of greater achievements in terms of ramp inclines; notably, $80 \%$ of the subjects who were active in sports, (ASE group Fig. 3), were able to ascend ramp inclines of $15 \%$, slightly more than double the achievements of the $80 \%$ of subjects of Figure 2 .

If the ramp traversability is required to be evaluated on the basis of the performances of the great majority of SSOH group, the prescriptions shown in Table IV can be adopted. The two ramps which were assembled in the Santa Lucia gymnasium had been designed on the basis of this assumption. Notably, not all the WDI

Table IV Ramp/grade relationship for wheelchair dependent individuals

\begin{tabular}{cc}
\hline Length of ramp (metres) & Grade (\%) \\
\hline 1 & 15 \\
3 & 12 \\
6 & 10 \\
\hline
\end{tabular}


who attempted to traverse, and subsequently successfully completed the task (both in the ascent and descent phases), pertained to the ASE group, although they pertained to the SSOH group as well.

\section{Discussion and conclusion}

Assuming architectural barriers to be eliminated, the range of the WDI population which could be accommodated becomes primarily a political choice. In fact, if the total population is to be considered, no incline at all should be adopted. In such instances, many public buildings, at least in our country, will likely remain inaccesible to WDI.

Taking into account only those subjects who, in this research, exhibited at least a minimal level of force availability, and on the basis of our previous findings, the following ramp length-grade relationships can be envisaged: (1) When we have no reasons to force the incline of ramps, a wise solution could be represented by an $8 \%$ ramp. This incline, which poses no practical limitations in terms of ramp length, can be easily traversed by the majority of the WDI population. It seems likely that subjects unable to manage with this low incline are so incapable as to require an external aid, such as a motorised wheelchair or an assist provided by another physically capable person and (2) When we are faced with public buildings that can not be easily altered in their structure, a maximum ramp incline of $15 \%$ for a ramp length of 1 metre, $12 \%$ for 3 metre, and $10 \%$ for 6 metre ramp length can be allowed.

The above guidelines are general, however, given the use of ramp length/grade relationships which resulted from our research, we could be expected to make homes, and especially public buildings, accessible to a majority of wheelchair dependent persons.

Furthermore, our results clearly indicate the importance of maintaining and/or improving upon, the WDI level of muscular fitness that represents the physical limiting factor of his/her performance. In this respect, the beneficial effects of sport participation on a regular basis for WDI is once again emphasised.

\section{Acknowledgement}

Support for this research was provided by a grant from Regione Lazio, Rome, Italy.

\section{References}

Cappozzo A, Felici F, Figura F, Marchetti M, Ricci B 1991 Prediction of ramp traversability for wheelchair dependent individuals. Paraplegia 29: 470-478.

CASS GC, CAMP EM 1979 Physiological characteristics of trained Australian paraplegic and tetraplegic subjects. Medical Science in Sports 11:256-259.

Cerquiglini S, Figura F, Marchetti M, Ricci B 1981 Biomechanics of wheelchair propulsion. In: Morecki A, Fiolelus K, Keolzioz K, Wit A, eds. Biomechanics VII-A:410-419.

ENGEL P, HILDEBRANDT G 1974 Wheel chair design-technological and physiological aspects. Proceedings of the Royal Society of Medicine 19:409-413.

Hildebrandt G, Voigt ED, BAHN D, Berendes B, KROGER J 1970 Energy cost of propelling wheel chair at various speeds: cardiac response and effect on steering accuracy. Archives of Physical Medicine and Rehabilitation 51:131-136.

Lehman FJ, Warren CG, Halar E, Stonebridge JB, De Lateur BJ 1974 Wheel chair propulsion in the quadriplegic patient. Archives of Physical Medicine and Rehabilitation 55:183-186.

MCLAURIN CA, BRUBAKER CE 1979 Wheel chair biomechanics. Disability, p. 471-477. 
SANDERSON DJ, SOMMER HJ 1985 Kinematic features of wheelchair propulsion. Fournal of Biomechanics 18:423-429.

Sawka MN, Glaser RM, Laubach LL, Al-Samkari O, Suryaprasad AG 1981 Wheelchair exercise performance of the young, middle-aged, and elderly. Fournal of Applied Physiology 50:824-828.

SAWKa MN, GLASER RM, WILDE SW, vON LUHRTE TC 1988 Metabolic and circulatory responses to wheelchair and arm crank exercise. Fournal of Applied Physiology 49:784-788.

StOBoy HB, WILSON-RICH W, LEE M 1971 Workload and energy expenditure during wheel chair propelling. Paraplegia 8:223-230.

Van Der Woude LHV, Hendrich KMM, Veeger HEJ, van Ingen Schenau GJ, Rozendal RH, DE Groote G, Hollander AP 1988 Manual wheelchair propulsion:effects of power output on physiology and technique. Medicine Science in Sports 20:70-78.

Van Der Woude LHV, De Groote G, van Ingen Schenau GJ, Rozendal RH 1986 Wheelchair ergonomics and physiological testing of prototypes. Ergonomics 29:1561-1573. 